\title{
A tecnologia lítica dos grupos horticultores no alto rio Paraná. O caso do sítio Corpus, Argentina.
}

Romina Silvestre (*)

SILVESTRE, R. A tecnologia lítica dos grupos horticultores no alto rio Paraná. O caso do sítio Corpus, Argentina. R. Museu Arq. Etn., 24: 25-40, 2014

Resumo: A arqueologia da província de Misiones - Argentina é pouco conhecida. Os trabalhos arqueológicos se desenvolveram há mais de 60 anos, e os mais recentes se limitam a descrições das coleções obtidas a partir da arqueologia de contrato. Esta situação esta começando a mudar a partir do desenvolvimento do projeto Binacional ABAMS (Arqueologia do Bosque Atlântico Meridional Sul-americano) entre Argentina e Brasil, que procura compreender o povoamento dessas áreas além das fronteiras nacionais desde uma perspectiva regional. Portanto, o objetivo deste trabalho é apresentar uma análise preliminar do material lítico recuperado no sítio Corpus, caracterizado como produzido por grupos Guarani. O objetivo último é estabelecer tendências gerais para compreender as estratégias tecnológicas dos grupos que produziram esses conjuntos, assim como contribuir com informação novel numa área pouco conhecida até hoje.

Palavras-chave: Tecnologia lítica, Tupiguarani, Alto Paraná, Argentina.

\section{Introdução}

\footnotetext{
arqueologia da Província de Misiones (Argentina) é pouco conhecida na literatura arqueológica argentina. Os artigos publicados são em sua maioria trabalhos que foram produzidos há mais de 60 anos, e a escassa produção atual se concentra majoritariamente em descrições das coleções obtidas a partir de trabalhos feitos no âmbito da arqueologia de contrato. Esta situação está começando a mudar

(*) Instituto Nacional de Antropología y Pensamiento Latinoamericano.<romisilvestre@gmail.com>
}

a partir do desenvolvimento do projeto "Arqueologia do Bosque Atlântico Meridional Sul -americano" (Projeto ABAMS) o qual pesquisa a região entre a província Argentina de Misiones e o Estado de Santa Catarina, no Brasil, e procura compreender o povoamento humano no alto rio Paraná sob uma perspectiva regional, entendendo a região como um todo que deve ser estudado além das fronteiras nacionais.

O objetivo deste trabalho é compreender as estratégias tecnológicas empregadas pelos grupos humanos que habitaram a região, a partir de um estudo de caso: a análise dos materiais líticos recuperados no sítio Corpus caracterizado como produzido por grupos Gua- 
rani (Carbonera e Loponte 2014; Loponte et al 2014; Silvestre e Capparelli 2014). Para tanto, o conjunto foi analisado a partir uma perspectiva dupla: por um lado a estrutura tecnomorfológica do conjunto foi avaliada, e por outro foram estudadas as matérias primas e sua disponibilidade num marco regional. Com isso pretende-se estabelecer tendências gerais dentro do conjunto analisado para compreender as estratégias tecnológicas dos grupos que habitaram a região. O objetivo último é aportar informação nova ao modelo arqueológico que esta sendo proposto, numa área pouco conhecida até hoje.

A arqueologia dos grupos de origem amazônica tradicionalmente conhecidos como Guarani na literatura argentina, tem sido objeto de interesse desde o inicio da disciplina arqueológica (Burmeister 1872; Ambrossetti 1895; Torres 1911; Outes 1917, 1918). No entanto, estes estudos tiveram um desenvolvimento intermitente e têm se centrado principalmente em descrições tipológicas ou estilísticas de coleções de conjuntos cerâmicos (um resumo deles pode ser encontrado em Loponte e Acosta 2008).

Recentemente, a Arqueologia de grupos Guarani tem sido objeto de um interesse renovado na Argentina graças à escavação de novos sítios, a re-localização de antigos sítios trabalhados por outros pesquisadores, assim como a implementação de novas metodologias de estudo. Como resultado uma enorme quantidade de informação nova sobre os diversos aspectos ligados às estratégias de subsistência, à organização econômica, à composição da dieta, assim como a aspectos ligados ao processo de colonização Guarani no Pantanal do rio Paraná inferior e no estuário superior do Rio da Prata (Acosta e Loponte 2002-2004; Acosta e Mucciolo 2009; Acosta et al. 2010a, 2010b; Bogan 2005; Capparelli 2007, 2014; Loponte e Acosta 2003-2005, 2007, 2008, 2013; Loponte et al. 2011a; Mucciolo 2007, Silvestre 2013). No entanto, pouco se conhece sobre outros aspectos do registro arqueológico Guarani, como a organização tecnológica e as estratégias de procura, obtenção e manejo de rochas destes grupos. Recentemente, foi publicado um trabalho sobre esta temática analisando o material recuperado no sítio Arroyo Fredes (Silvestre 2013). Portanto, o alvo deste artigo é contribuir com informação original sobre as estratégias tecnológicas destes grupos, um aspecto do registro pouco conhecido ate o momento.

É evidente que o estudo sobre organização tecnológica é uma das ferramentas principais entre as que permitem formular e avaliar hipóteses sobre aspectos fundamentais da subsistência humana do passado. Neste sentido, se considera à organização tecnológica como uma estratégia de análise que tenta esclarecer as variadas formas em que a tecnologia lítica se encontra integrada (embedded, Binford 1979) dentro das escolhas, decisões e atividades que desenvolveram seus usuários e produtores, num meio natural e cultural particular (Andrefsky 2005). Como anteriormente dito, os escassos trabalhos que tratam do registro lítico Guarani em geral são basicamente descritivos (Luz e Faccio 2006; Alonso e Prous 2003; Pestana 2007; Wagner 2003; Hoeltz 2005, entre outros) deixando de fora enfoques teórico-metodológicos mais ricos que poderiam fornecer uma quantidade maior de informação ligada a aspectos mais gerais do registro, como as estratégias de predação ou subsistência das sociedades estudadas (Silvestre 2010).

Por outro lado, existe outro grande problema que é a assignação etnológica dos conjuntos, a qual deriva da perspectiva histórico-cultural com a qual frequentemente se trabalha. Deste modo, gerou-se um grande debate sobre quais são os tipos artefatuais que pertenceram aos Tupi pré-históricos e quais aos Guarani pré-históricos (para uma discussão ver Prous 2011). Os limites são difusos, sobretudo no sul do Brasil onde se presume que existiu certa coexistência e houve ocupação dos mesmos espaços (Moraes 2007; Lopes e Moraes 2009; Afonso, Sallum e Lopes 2010), como nos casos de sítios que são assinalados como Tupi, e que logo foram reocupados por grupos Guarani. O problema maior é consequência da terminologia que se utiliza para nomear a estes grupos: o que se chama Tradição Tupiguarani; Tradição Tupi; Subtradição Guarani, etc. (Prous 2011). Estas confusões refletem um velho problema já conhecido na Arqueologia: o uso, nestes casos, de estilos decorativos ou grupos tipológicos cerâmicos 
para a diferenciação "arqueológica" de grupos étnicos reconhecidos em tempos históricos. Desta forma, são poucos os estudos que procuram ultrapassar estes enfoques e assim logrem resolver questões mais gerais, como as técnicas de obtenção e processamento de recursos; a circulação de bens e matérias primas; ou as estratégias tecnológicas utilizadas pelos grupos para solucionar as incongruências espaciais e temporais na disponibilidade e localização dos recursos.

Na Argentina, e mais precisamente no Alto rio Paraná poucos trabalhos tratam sobre conjuntos provenientes de sítios relacionados a ocupações Guarani (Acosta e Mucciolo 2009, Silvestre 2013). Esta falta de informação pode estar ligada à problemas de amostragem na localização de novos sítios (uma discussão pode ser vista em Loponte et al 2011); mas também à possibilidade de que essas áreas tenham sido ocupadas apenas nos últimos séculos antes da conquista espanhola, e também ao fato de que a Bacia do Paraná e rio da Prata foram o limite meridional da expansão destas populações de origem amazônica (Noelli 2004; Brochado 1984). As investigações que vêm se desenvolvendo nesta região consideram a localização, relocalização e escavação de novos e velhos depósitos arqueológicos correspondentes a estes grupos. Neste sentido, este trabalho contribuirá a estas pesquisas, sendo nosso principal alvo analisar a estrutura tecnomorfológica do conjunto lítico recuperado no sítio Corpus, assim como explorar alguns índices ligados a exploração de matérias primas. $\mathrm{O}$ alvo geral è contribuir com informação original ao estudo das populações Guarani, um dos grupos mais relegados na Arqueologia Argentina.

\section{Antecedentes}

Como foi mencionado anteriormente, na Argentina são poucos os trabalhos que discutem materiais Guarani, sendo o panorama ainda mais restrito quando se trata do estudo da tecnologia lítica guarani. $\mathrm{O}$ estudo da arqueologia Guarani na província de Misiones tem se desenvolvido de uma maneira intermitente.
Desta forma se, em seu começo, a pesquisa da arqueologia argentina na área foi um referencial para a arqueologia brasileira, o seu desenvolvimento na segunda metade do século $\mathrm{XX}$ foi muito menos intenso e muito mais disperso.

$O$ primeiro trabalho que faz referencia a artefatos líticos achados em contextos Guarani é o trabalho de Ambrossetti (1893) que publica, entre outros achados, uma lâmina de machado proveniente do Alto Paraná, um tembetá feito de resina, uma mão de pilão e lascas (Misiones). Além desses achados, Ambrossetti foi o primeiro em vincular esses objetos arqueológicos aos Guarani históricos, e em vincular o registro material encontrado ao norte do país àquele recuperado na desembocadura do sistema Paraná - Prata, concluindo que se tratava das mesmas populações, e relacionando registros arqueológicos distantes mais de $1500 \mathrm{~km}$ de distancia (Loponte e Acosta 2013). No começo do século XX, Métraux fez um estudo da cultura material dos grupos Tupi e Guarani, a partir de um ponto de vista etnográfico (1928), enquanto Menghin $(1955-56,1957,1962)$ fez estudos sistemáticos e regionais que, ainda que fossem trabalhos enfocados em estudos de tradições e fases arqueológicas, serviram de referência à Arqueologia brasileira da época. Outros trabalhos da época são os publicados por Rizzo (1968, 1969), que faz neste ultimo caso um estudo de ateliês líticos no Alto Paraná (Rizzo 1969).

Já nos finais do século XX, Mujica publicou um informe de sítio interessante, já que no sítio Llamarada, no centro da província de Corrientes, ele identificou entre outros materiais, artefatos de osso, como pontas e agulhas, os quais são raramente encontrados em contextos Guarani, e artefatos líticos como lascas de arenito silicificado, e dois calibradores de arenito friável (Mujica 1995a). Outros antecedentes importantes são os trabalhos produzidos também na década de 1990 (Caggiano e Prado 1991; Rodriguez 1994, 1996; Poujade 1995; Sempé e Caggiano 1995) e os publicados nos anos 2000 (Sempé e Rizzo 2000; Rizzo e Schimko 2003; Rodriguez 2003, 2004), no entanto ou eles não tratam o registro lítico guarani de modo algum ou fazem referencia apenas a alguns achados limitando-se a descrevê-los. 
Por outro lado, no outro extremo da distribuição geográfica destes grupos, Outes (1917) referiu a presença, entre outros materiais, de duas lascas de sílex achadas no sítio Puerto Viejo, na ilha Martin García, na porção final da bacia do Paraná em uma área conhecida como Pantanal do Paraná Inferior (Loponte 2008). No mesmo ano, publicou um trabalho sobre os materiais recuperados do sítio Arroyo Largo, localizado na mesma área, pela primeira vez dando conta do achado de um calibrador num sítio Guarani da Argentina (Outes 1918).

Porém a primeira descrição detalhada de um conjunto lítico guarani foi feita por Lothrop (1932), que escavou o sítio Arroyo Malo. Lothrop não só fez a descrição e a ilustração dos artefatos polidos, como também publicou os artefatos lascados, os quais não eram de maior interesse para os pesquisadores da época. Dentro do conjunto, Lothrop também achou um machado aparentemente confeccionado em basalto (Silvestre 2013). Alguns anos mais tarde, Vignati (1936) publicou os resultados das escavações realizadas no sítio Arenal Central, com achados de material lítico, entre os quais uma lâmina de machado. Já em meados do século XX, Eduardo Cigliano publicou os materiais recuperados no sítio El Arbolito (Cigliano 1968) na ilha Martin García. Posteriormente Capparelli (2014) relocalizou, na área de dunas, o sítio Arenal Central pesquisado anteriormente por Vignati, recuperando nele grandes quantidades de material lítico que incluiu dois fragmentos de lâminas de machado, artefatos polidos, afiadores de arenito silicificado e artefatos talhados como núcleos e lascas com rastros de uso.

No ano 2003 Loponte e Acosta relocalizaram o sítio Arroyo Fredes, previamente escavado por Gaggero, produzindo uma grande quantidade de trabalhos que exploraram diferentes aspectos do registro Guarani, como a dieta, o uso do espaço, as estratégias de subsistência e a cerâmica (Acosta et al. 2010a, 2010b; Loponte e Acosta 2003-2005, 2007, 2008; Loponte et al. 2011). Contudo, o primeiro estudo das estratégias tecnológicas empregadas por grupos Guarani na Argentina, foi o feito sobre materiais do sítio Arroyo Fredes (Silvestre 2013).

\section{O sítio Corpus}

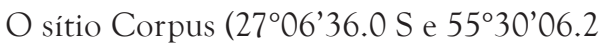
W) encontra-se localizado na eco-região Bosque Atlântico meridional, sub-região selva paranaense (Olson et al. 2001; Josse et al. 2003) na província de Misiones, no trecho nomeado Alto Paraná na beira mesma do rio, numa cota de $130 \mathrm{~m}$ (fig. 1). Efetuaram-se diversas sondagens para delimitar o sítio, estimando-se sua área total em aproximadamente $3750 \mathrm{~m}^{2}$ (Loponte, Carbonera e Acosta 2014). A superfície escavada ate o momento conforma um total de $18 \mathrm{~m}^{2}$ dividida em quadras de $2 \times 3 \mathrm{~m}$. A estratigrafia do sítio é composta por um estrato de areias fluviais atuais de cerca de $50 \mathrm{~cm}$, um estrato de terra preta antropogênica (TPA) que varia entre 50 e $70 \mathrm{~cm}$ de espessura dependendo da área escavada, e no qual foram achados os materiais arqueológicos, e outro estrato de areias fluviais depositadas pelo rio Paraná, estéril arqueologicamente (fig. 2). Entre os materiais recuperados foi achada grande quantidade de fragmentos cerâmicos, abundantes artefatos líticos e escassos restos faunísticos. O sítio foi datado por datação radiocarbônica, obtendo-se duas datas: a primeira, feita sobre um osso de mamífero indeterminado deu como resultado uma antiguidade de $459 \pm 43$ anos AP (AA 103647), a segunda datação, feita sobre amostra de osso humano coletada em um setor mais profundo da TPA, deu como resultado $495 \pm 20$ anos AP (USIAMS 134675) (Loponte, Carbonera e Acosta 2014).

\section{Materiais e Métodos}

O material analisado até o momento corresponde a uma amostra de aproximadamente $40 \%$ dos materiais recuperados da escavação das três quadras e de um setor que corresponde a uma limpeza do perfil existente junto à beira do rio. A amostra é composta por 128 artefatos, dos quais 17 correspondem a artefatos polidos, cinco correspondem a rochas não modificadas, dois correspondem a fragmentos de tembetás, e o restante (N: 104) são artefatos obtidos por lascamento. A análise tecnomorfológica dos 


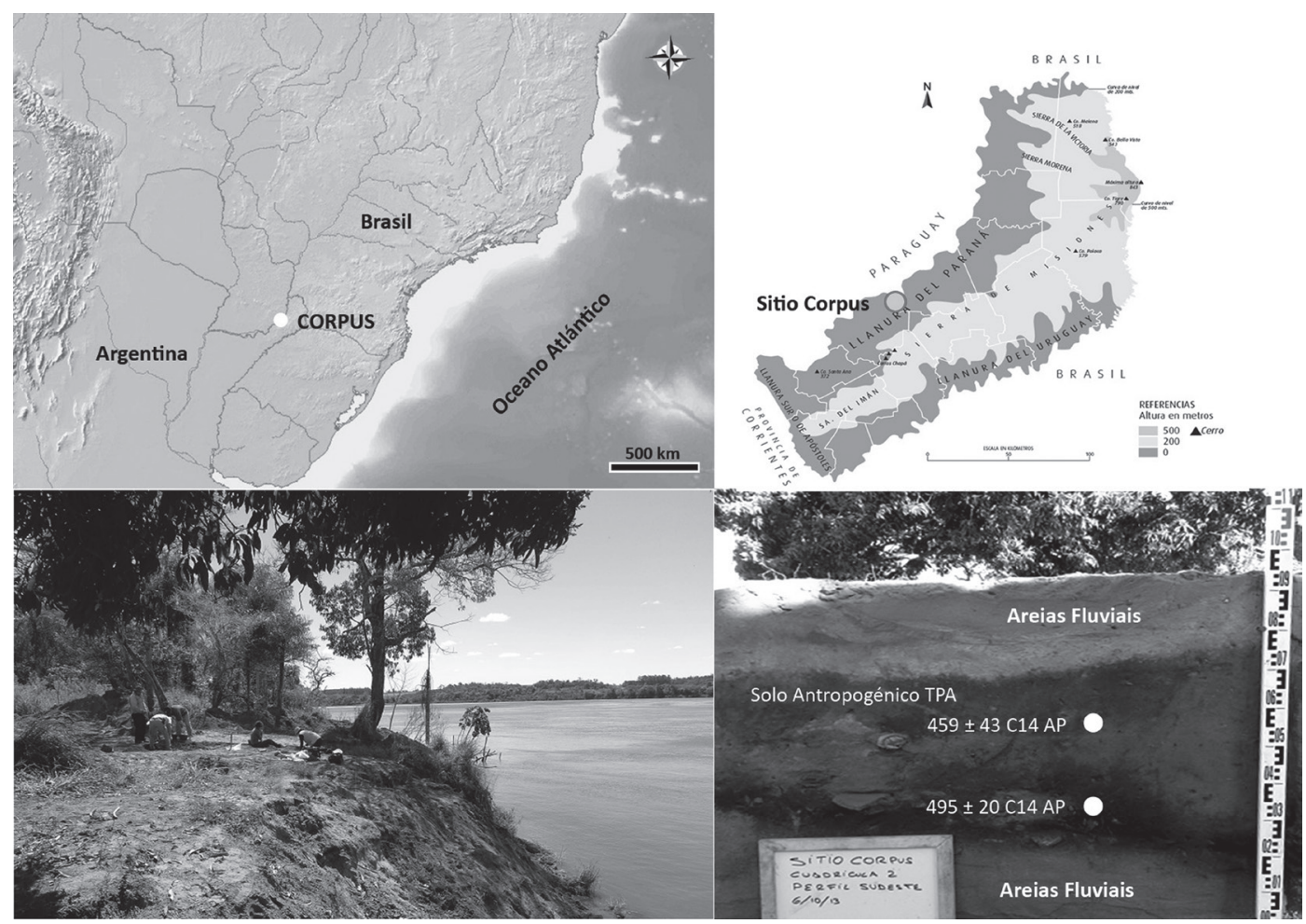

Fig. 1: Localização e estratigrafia do sítio Corpus.

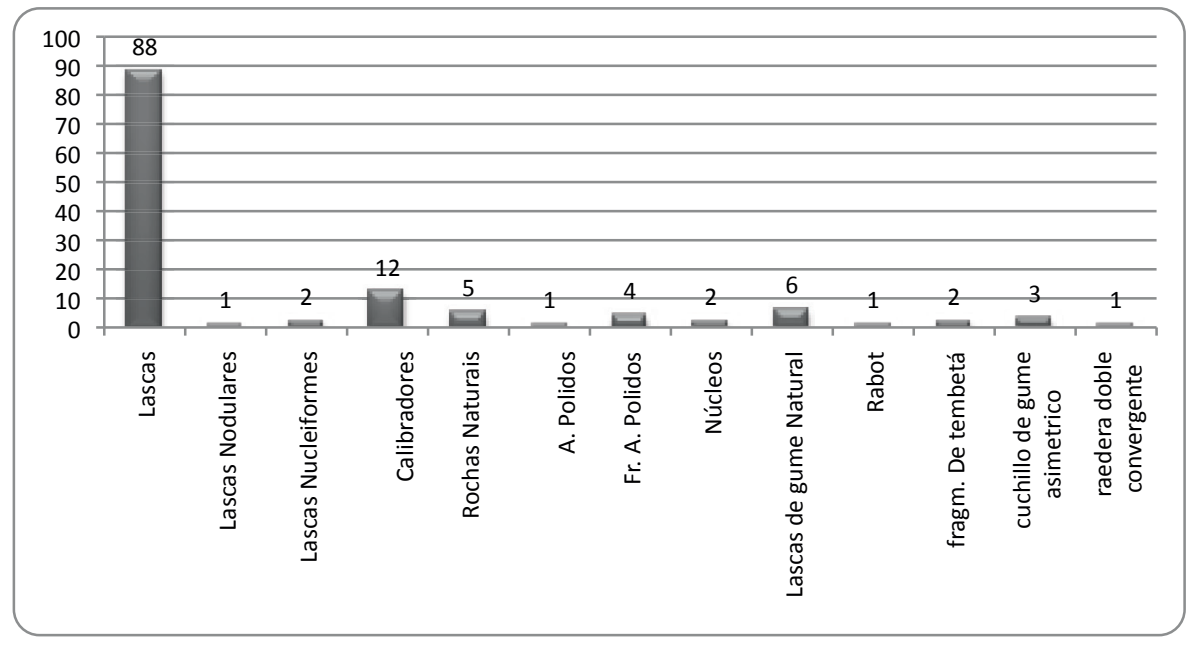

Fig. 2: Grupos tipológicos presentes no sítio Corpus.

materiais foi feita segundo as propostas metodológicas de Aschero (1975, 1983). Do mesmo jeito, utilizam-se diversos índices e métodos estatísticos comumente usados na análise da tecnologia lítica (Newman 1994; Brantingham 2003; Andrefsky 1994, 2005; Blumenschine et al. 2008) para explorar diversos aspectos tecnológicos, e da exploração das matérias primas. 


\section{Análise da Amostra}

Análise tecnomorfológica

Como se observa na figura 2, os artefatos mais abundantes no conjunto são as lascas em sentido amplo (lascas, lascas nodulares, lascas nucleiformes e lascas de gumes cortantes sem retoque) as quais totalizam 97 artefatos. As lascas nucleiformes são poucas (N: 2), e os núcleos também (N: 2). Além do anteriormente dito, a presença desses artefatos, somados a presença de microlascas, evidenciam a execução de processos de lascamento no sítio.
Por outro lado, os artefatos retocados são poucos. Ainda que o índice de retoque seja baixo $(3,96 \%)$ na amostra até agora analisada, é notável a presença de um rabot (fig. $3 \mathrm{~g}$ ) com grandes retiradas e microretiradas em bisel abrupto, um raspador duplo convergente (fig. $3 \mathrm{~h}$ ), com gumes compridos, com retoques e microrretoques bifaciais, e ângulos entre 34 e $54^{\circ}$, e três artefatos com os gumes retocados por microrretoques unifaciais de fios assimé-

1 Esses artefatos são raspadores de grande tamanho. As hipóteses para seu uso são varias, sendo a mais aceita a de que foi utilizado para o processamento de recursos vegetais como a raspagem de madeira (Aschero 1975, 1983).

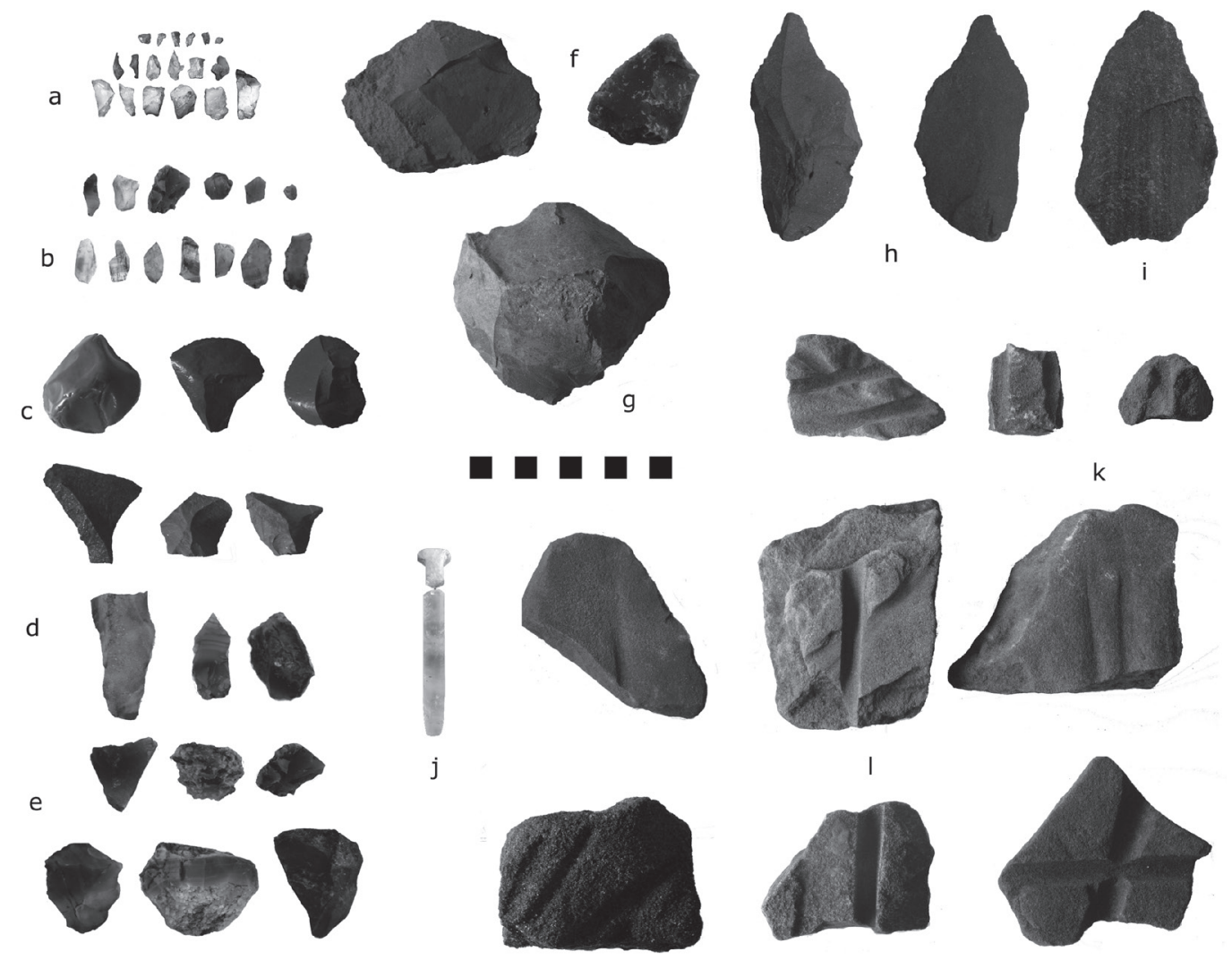

Fig. 3: Variedades de artefatos e matérias primas recuperados no sítio Corpus. a. e b. lascas em quartzo e rodados silícios, c. lascas nodulares, d. lascas de gume natural em arenito silicificado e sílex, e. lascas nucleiformes, f. facas retocadas de bisel assimétrico (arenito silicificado e calcedônia), g. rabot, h. raspador duplo convergente, i. faca retocada de bisel assimétrico em arenito silicificado, j. fragmentos de tembetás em quartzo, k. fragmentos de calibradores em arenitos silicificado friável, 1. calibradores. 
tricos (fig. 3 f e i). O tamanho dos artefatos obtidos por lascamento é muito variável, dependendo da matéria prima utilizada (fig. 3). O mesmo pode ser dito em relação com as técnicas de obtenção de lascas. De fato, o lascamento direto (unipolar) foi utilizado predominantemente para o trabalho do arenito silicificado, enquanto que o lascamento bipolar foi aplicado aos seixos rolados e seixos de silex e ao quartzo. Todos os artefatos retocados foram retocados unifacialmente, excetuando o raspador duplo convergente, que foi retocado bifacialmente. $\mathrm{O}$ comprimento dos artefatos retocados é importante (X: 48,03 mm), o que se encontra também vinculado à preferência pelo arenito silicificado para a confecção dos artefatos retocados.

Quanto aos artefatos polidos, chama a atenção a grande quantidade de calibradores e fragmentos de calibradores que totalizaram 12 na amostra analisada até agora (fig. 3, k e l), todos confeccionados em arenito friável. De fato, também se registrou a presença de um desses artefatos confeccionado em cerâmica (Silvestre e Buc 2015). As hipóteses de uso destes artefatos variam entre: regularização de hastes de projétil, produção de tembetás, e calibração de contas de colar (Léry 1972 [1556-1558]; Lima 2005; Lima e Souza 2005; Prous 2011). De acordo com o que postula Prous (2011) eles não superam os sete $\mathrm{cm}$ de comprimento. A largura dos sulcos desses artefatos (fig. 4) é altamente variável, oscilando entre $3,41 \mathrm{~mm}$ e $12 \mathrm{~mm}$, com uma media de 7,08 $\mathrm{mm}$ e um coeficiente de variação de $31,61 \%$. Estes artefatos são diferentes dos recuperados em outros sítios (i.e. Arenal Central), sendo a principal diferencia a morfologia das canaletas ou sulcos. De fato, os artefatos do Sitio Corpus apresentam canaletas com fundo em forma de U, o que está em acordo com as principais hipóteses de uso propostas (fig. 3). No caso das canaletas presentes nos artefatos de Arenal Central (Capparelli 2014) os sulcos apresentam fundo em forma de $\mathrm{V}$, o que sugere que poderiam ter sido utilizados como afiadores de gumes de artefatos.

Por outro lado, ao contrário do que ocorre tanto em muitos sítios brasileiros como em outros sítios na Argentina (Ambrossetti 1893, Outes 1918, Capparelli 2014), no sítio Corpus ainda não foram recuperadas lâminas de machado. É notável também a presença de duas rochas naturais polidas provavelmente utilizadas como alisadores de cerâmica (Prous

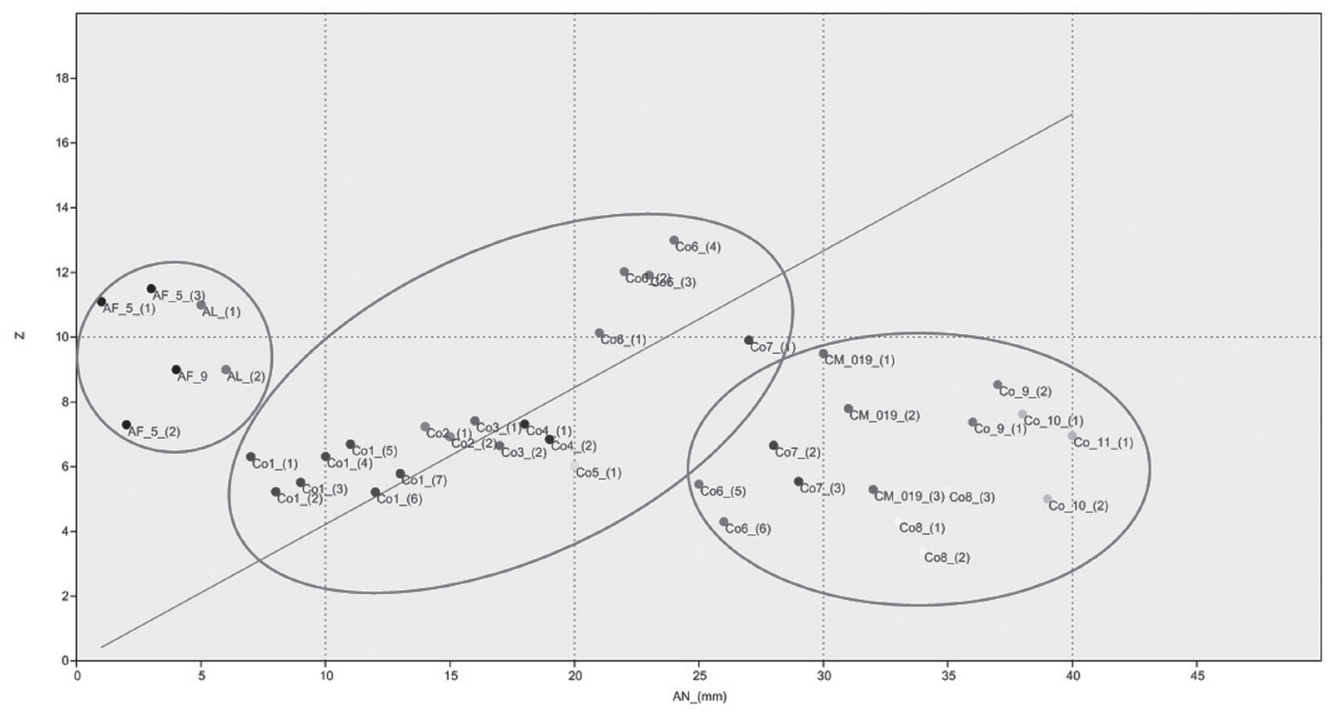

Fig. 4: Comparação de largura dos sulcos dos calibradores procedentes de vários sítios guaranis argentinos. AF: Arroyo Fredes (Pantanal do rio Paraná Inferior), Co: Corpus (Misiones), AL: Arroyo Largo (Pantanal do rio Paraná Inferior), CM: Coleção Museo Chapecó - CEOM (SC, Brasil). 
2011). Por último, destaca-se a presença de dois fragmentos de tembetás de quartzo hialino (fig. $3 \mathrm{j}$ ), um extremo proximal com forma de T, e um fragmento comprido até o extremo distal (c. $7 \mathrm{~cm}$ ), produzido por polimento de um grande cristal de quartzo.

\section{Análise das matérias primas}

Na figura 5 pode-se observar a variabilidade de matérias primas presentes no sítio Corpus. $\mathrm{O}$ arenito apresenta duas variedades. Por um lado, o arenito quartzoso, friável, uma rocha sedimentar com que foram produzidos os calibradores. Essa rocha, que apresenta diferentes graus de friabilidade, é formada por areias de diferente granularidade que podem se encontrar cimentadas por processos diversos, às vezes por um cimento silícoso (arenito silicificado), outras por se encontrar em intercalações com o basalto da Formação Serra Geral, situação na qual se forma um quartzito de fratura conchoidal (INSU. GEO 2007; Grupo Consultor Mesopotámico 2006-2009; Remesal y Chávez 2014). Essa rocha foi a mais utilizada para a produção de artefatos (fig. 5) já que aflora em Corpus mesmo, e nas vizinhanças na localidade de San Ignacio (INSUGEO 2007; Grupo Consultor Mesopotámico 2006-2009).
Em seguida, em importância, aparecem os materiais silicosos em geral (seixos de sílex, calcedônia e sílex), Estas rochas pertencentes à Formação Ubajay e encontram-se, junto ao quartzo, aflorando perto da Capital de Misiones (Posadas) e na área de San Javier, na beira do rio Uruguay (INSUGEO 2007; Grupo Consultor Mesopotámico 2006-2009) e possuem qualidades variáveis para o lascamento. Além do anteriormente dito, a Formação Serra Geral apresenta vesículas e amígdalas que se encontram geralmente preenchidas por calcedônia e opala, indicando que esses materiais silicosos poderiam ser obtidos das duas formações. Por último, ainda que o basalto conforme quase 90\% do território da província de Misiones (INSUGEO 2007), a importância desta rocha dentro das estratégias tecnológicas utilizadas pelas populações que ocuparam o sítio Corpus, não foi grande. Como se pode observar na figura 5, esta rocha ocupa o último lugar em importância.

Por outro lado, se as estratégias de manejo das matérias primas forem consideradas, é interessante pensar sobre certos aspectos do registro. Desta forma, as lascas que apresentam restos de córtex em algumas das faces representam o $11 \%$ da amostra, evidenciando que os seixos e as rochas locais eram utilizados, mas não existiu uma estratégia de economia da

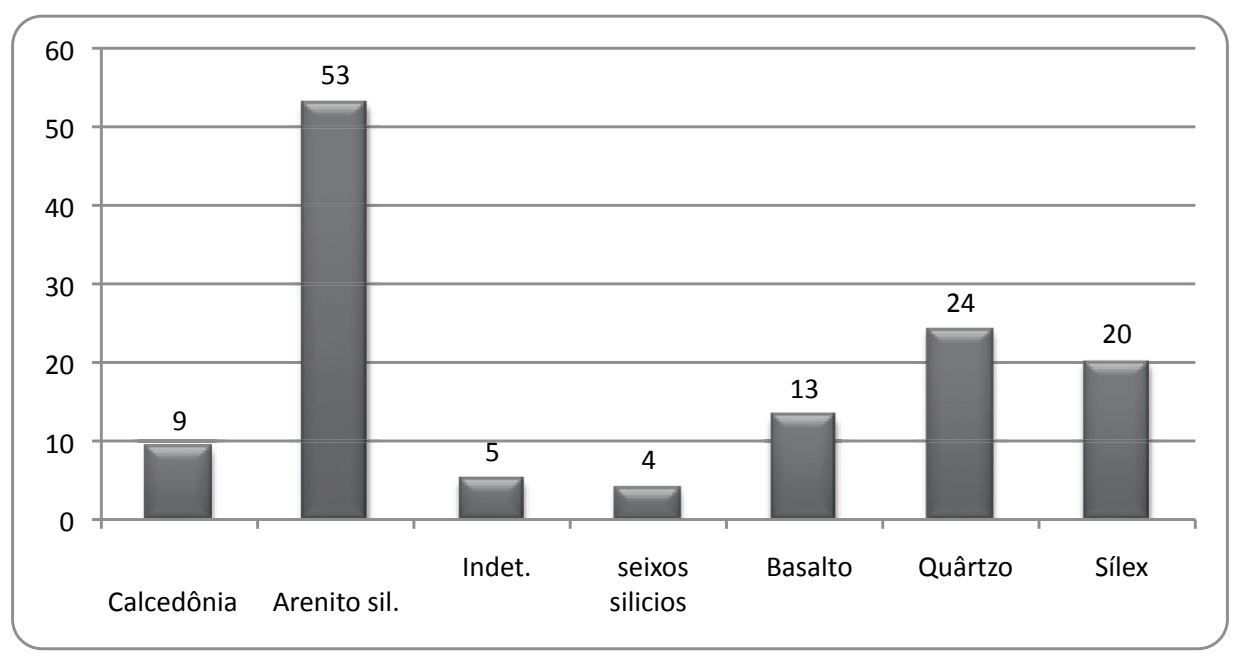

Fig. 5: Matérias primas representadas no sítio Corpus. 
matéria prima. Neste caso a técnica bipolar de obtenção de lascas, foi utilizada para determinadas matérias primas, como os seixos de sílex de tamanho pequeno, que não podiam ser exploradas através do lascamento direto ou unipolar. $\mathrm{O}$ mesmo pode ser dito quanto aos núcleos e seus tamanhos. As dimensões deles ficam em torno dos cinco centímetros e ainda apresentam potencial extrativo, ou seja, não se encontram esgotados, como se esperaria numa estratégia como a anteriormente dita. O mesmo ocorre se analisamos o tamanho dos artefatos. Aqueles produzidos em arenito silicificado são maiores, e rondam entre os 70 e os $90 \mathrm{~mm}$, ao contrário dos artefatos em materiais silícosos e quartzo que raramente superam os $20 \mathrm{~mm}$ (fig. 3a e h).

Por ultimo, é interessante salientar que existe uma baixa porcentagem de artefatos com alterações térmicas (8,59\%), como mudanças na coloração das rochas, estilhaçamento, e concavidades. Estas alterações não parecem ser produto da busca de melhoramento das propriedades da matéria prima, mais sim da exposição não controlada delas ao fogo como no caso de descarte em uma fogueira.

\section{Discussão}

Em relação aos aspectos tecnomorfológicos é claro que o grupo morfológico de maior representatividade é o grupo das lascas em geral. A grande abundância delas junto com a presença de microlascas e núcleos indica o desenvolvimento de atividades de extração e lascamento no próprio sítio. Esta interpretação é sustentada também pela presença de lascas corticais. Além dos artefatos retocados serem poucos, o índice de retoque é similar ao registrado em outros sítios Guarani da Argentina (Silvestre 2013). Isto, juntamente com a presença de lascas nodulares e a presença de núcleos com potencial de extração permite-nos concluir que se desenvolveram atividades de talha no sítio Corpus. A presença de um rabot no conjunto lítico pode indicar atividades ligadas ao processamento de matérias primas vegetais, como o raspar ou o aplainar de madeiras. Dado o grande tamanho do artefato podemos pensar em atividades ligadas ao acabamento de cabos de machado, ou outras atividades talvez ligadas à roça e queima. Estas hipóteses de uso, no entanto, só poderão ser referendadas através de análises traceológicas no artefato (Silvestre 2010, 2013).

Quanto às técnicas de obtenção dos artefatos, parece existir um predomínio do lascamento unipolar sobre o bipolar ou o lascamento sobre bigornas, diferindo muito do que ocorre no Brasil onde a maioria do material lítico descrito é de produção bipolar (Prous 2011). Além do anteriormente dito, é também notável o tamanho dos artefatos retocados em arenito silicificado.

Tal como postula Prous (2011), os conjuntos líticos descritos para sítios Guarani no Brasil são quase sempre considerados como "simples, ou empobrecidos", e quando são encontrados conjuntos mais diversos e numerosos em geral eles são considerados como relacionados a sítios de caçadores-coletores que teriam sido reocupados por grupos Guarani (Prous 2011). O caso do sítio Corpus parece sustentar a hipótese contraria. Tanto as técnicas de obtenção de lascas como o tamanho dos artefatos em arenito silicificado indica o emprego de estratégias de manejo das matérias primas. É claro que a maior disponibilidade de rochas numa área relativamente próxima ao sítio afeta o modo de produzir artefatos (Newman 1994, Brantingham 2003; Andrefsky 2005). Portanto, é fundamental na análise dos conjuntos líticos considerar não apenas a estrutura tecnomorfológica, mas também conhecer e incorporar na análise a localização das fontes de matérias primas em nivel regional, assim como determinar como elas afloram. Vincular esses dados à análise permite obter uma visão global, assim como entender de uma maneira mais abrangente as estratégias tecnológicas empregadas pelos grupos estudados

No que concerne aos artefatos polidos, é notável a grande quantidade de calibradores registrados no sítio Corpus em comparação a outros sítios Guarani argentinos. Na região do Pantanal do rio Paraná inferior, se contabilizou até agora apenas três destes artefatos, dois no sítio Arroyo Fredes (Silvestre 2013) e um no sítio Arroyo Largo (Outes 1918, Silvestre 2013). Um outro foi registrado no sítio Llamarada em 
Corrientes (Mujica 1995b). No sítio Corpus, por outro lado, foram registrados até agora 12 calibradores, sem que seja possível no momento indicar que fator poderia ser responsável por esta diferença.

Como fica perceptível na figura 3, existe uma variação na largura dos sulcos dos calibradores. A presença de calibradores no registro arqueológico é assumida na literatura brasileira como uma indicação da fabricação de pontas (Morales 2005; Hoeltz 2005; Prous 2011; Milheira 2009). Se os calibradores foram efetivamente utilizados para a confecção de hastes de projéteis, esta diferença poderia estar ligada à confecção de hastes de tamanho diferente, talvez indicando a utilização de pontas de diversos tamanhos. No entanto nenhuma ponta de projétil foi achada, até o momento, no sítio Corpus, o que poderia ser explicado a partir de três possibilidades: (1) as pontas líticas, embora existentes no sítio, ainda não foram recuperadas, (2) as pontas eram confeccionadas em madeira e não sobreviveram no registro arqueológico, ou (3) os calibradores foram utilizados para a confecção de outros artefatos.

No sítio Arroyo Fredes outro sítio Guarani escavado por nós, mas localizado no Pantanal do rio Paraná inferior, foi recuperada uma ponta de projétil em sílex, a primeira encontrada em um sítio Guarani na Argentina, e dois calibradores (Silvestre 2013). A ausência de pontas de projétil líticas no sítio Corpus está em acordo com o que acontece na maioria dos sítios Guarani do sul brasileiro, porém, De Masi e Schmitz (1987) mencionam a presença destes artefatos nos conjuntos guarani do Rio Grande do Sul. Contudo, não são artefatos comumente achados em sítios Guarani e a associação dos calibradores com a fabricação de hastes de projétil é mais assumida que demonstrada. A funcionalidade destes artefatos só poderá ser provada através de análises traceológicas (Silvestre 2010).

Os fragmentos de tembetá achados, feitos em quartzo hialino, são tanto morfologicamente como na matéria prima, idênticos aos achados nos sítios meridionais do Brasil (Prous 2011). Por fim é interessante salientar que ainda não foram achados lâminas de machados ou cunhas no sítio Corpus.
Em relação às matérias primas, é notável a preferência pelo arenito silicificado para a confecção de artefatos retocados e de grande porte, o qual predomina sobre as demais matérias primas. Esta preferência pode estar ligada tanto às propriedades mecânicas desta rocha, como ao packaging das outras. De fato, a segunda matéria prima mais comum é constituída por rochas silicosas em termos gerais. A calcedônia, os seixos de sílex e o sílex são todas rochas disponíveis na forma de rolados que procedem muito provavelmente da formação Ubajay, e que possuem entre 2 e $10 \mathrm{~cm}$ de comprimento (Grupo Consultor Mesopotâmico 2006-2009). Estes diâmetros provavelmente limitaram o tamanho final dos artefatos e fez com que fossem transformados através da técnica bipolar, e com que fossem utilizados como gumes cortantes sem retoque. Por outro lado, o arenito silicificado de fratura conchoidal se encontra disponível de maneira local dentro dos interstícios dos derramamentos basálticos por toda a província de Misiones (Remesal e Chavez 2014), inclusive na área da cidade de Corpus (INSUGEO 2007).

Recentemente, foi salientado o fato de acharmos artefatos destes tamanhos em sítios Guarani (Milheira com. pess. 2014; Rogge com. pess. 2014)2. Contudo, achamos que as decisões tecnológicas dos grupos que analisamos se baseiam no conhecimento da estrutura lítológica regional, da disponibilidade e acessibilidade das rochas, e no conhecimento das propriedades mecânicas destas. Neste caso, a excelente qualidade do arenito silicificado para lascamento, junto com a sua acessibilidade e disponibilidade local, fez que esta matéria prima fosse selecionada para produzir artefatos grandes com gumes retocados, alguns deles de maneira bifacial e, talvez, orientados a desenvolver determinadas tarefas que ainda não podem ser inferidas. Outra vez, só quando se desenvolverem estudos traceológicos será possível propor hipóteses concretas sobre a sua funcionalidade. Talvez a

2 Esses comentários foram feitos no Simpósio "Arqueologia da Mata Atlântica Meridional Sul Americana" durante o 20 Congresso Internacional de Arqueologia da Bacia do Prata, San José de Mayo 7-11 de abril de 2014. 
diferença entre os achados no sítio Corpus e outros achados em sítios Guarani em regiões meridionais brasileiras resida no fato destas apresentarem menor disponibilidade de grandes afloramentos de rochas de fratura conchoidal.

Finalmente é importante ressaltar que, além da presença conspícua dos afloramentos de basalto em toda a província, a importância desta rocha dentro do conjunto lítico encontrado no sítio Corpus é desprezível. Talvez esta sub-representação possa se dever á maior disponibilidade na área de rochas de fratura mais previsível como o arenito silicificado.

\section{Considerações finais}

Como afirma Prous (2011), a tecnologia lítica guarani no Brasil geralmente foi caracterizada como pobre, mencionando-se como únicos achados as lâminas de machados, os tembetás e as lascas de gumes cortantes sem retoque. Além disso, conjuntos mais diversos são sempre vinculados a sítios caçadores- coletores reocupados pelos Guarani. Esta visão reducionista da tecnologia lítica guarani é produto da preponderância dada às descrições tipológicas, não se considerando de maneira mais global as relações da tecnologia com o manejo e tratamento da matéria prima. Infelizmente, são poucos os trabalhos que fazem uma análise profunda das relações entre a tecnologia e os recursos líticos disponíveis em escala regional.

No entanto, tanto neste artigo como outros (Silvestre 2013, Silvestre e Capparelli 2014), alguns pesquisadores estão começando a propor uma mudança de idéias sobre a tecnologia guarani, deslocando o foco para as estratégias tecnológicas utilizadas pelos grupos estudados. A diversidade da tecnologia lítica achada no sítio Corpus provavelmente esteja ligada com a variável disponibilidade da matéria prima nas áreas analisadas. As tendências evidenciadas nesta análise preliminar do sítio Corpus, deverão ser contrastadas com a análise do restante do conjunto. É claro que estas tendências poderão ser reforçadas com a escavação de mais sítios Guarani na Argentina, assim como com a comparação deste registro com o proveniente de outros sítios Guarani da bacia do Paraná.

\section{Agradecimentos}

O presente trabalho contou com o apoio financeiro das seguintes instituições: Agencia Nacional de Investigación Científica y Tecnológica PICT2011-2035 e PICT-2012-1261, CONICET PIP2012-11220110100565 e CIC2011 4541-12. O Centro da Memória do Oeste Catarinense (CEOM - UNOCHAPECÓ) contribuiu com o apoio de um estágio de análise de materiais depositados nessa instituição. Agradeço os diversos comentários e ideias discutidas com: Isabel Capparelli, Daniel Loponte, Alejandro Acosta e Mirian Carbonera. Por último, desejo agradecer à equipe editorial da Revista do MAE que gentilmente contribuiu com correções gramaticais do português, melhorando enormemente a qualidade do mesmo. Contudo, as ideias expostas neste trabalho são de responsabilidade exclusiva da autora. 
SILVESTRE, R. Lithic technology of South American horticulturalist groups from upper Paraná River. The case of Corpus site, Argentina. R. Museu Arq. Etn., 24: 25-40, 2014.

\begin{abstract}
The archaeology of Misiones province is poorly known. Archaeological works were developed over 60 years ago, and those recently carried out, are based on typological descriptions of collections recovered from rescue and contract archaeology. This situation is beginning to change since the creation of the ABAMS Binational Project between Argentina and Brazil that seeks to understand the peopling of this area beyond national frontiers from a regional perspective. Thus, the goal of this paper is to present a preliminary analysis of the lithic material recovered from Corpus site, characterized as being produced by Guaraní groups. The main purpose is to establish general tendencies in order to understand the technological strategies employed by the people that produced these artifacts, and to contribute with novel information in an area poorly known until now.
\end{abstract}

Keywords: Lithic technology; Guaraní; upper Paraná river; Argentina.

\title{
Referências Bibliográficas
}

Acosta, A. e Loponte, D. 2002/2004. Presas y predadores: avances en la composición isotópica de la dieta de los grupos prehispánicos del sector centro-oriental de la Región Pampeana. Arqueología 12: $105-134$.

Acosta, A.; Loponte, D. e Mucciolo, L. 2010a. Uso del espacio y subsistencia de grupos horticultores amazónicos en el humedal del Paraná inferior. Arqueología Rosarina hoy 2: 35-55.

Acosta, A.; Loponte, D. e Mucciolo, L. 2010b. Comparando estrategias de explotación faunística en el humedal del Paraná inferior: cazadores-recolectores vs. horticultores amazónicos. In Gutiérrez, M.A.; De Nigris, M.; Fernández, P.M.; Giardina, M.; Gil, A.; Izeta, A.; Neme, G. e Yacobaccio H. (Eds.) Zooarqueología a principios del siglo XXI. Aportes teóricos, metodológicos y casos de estudio, 177-188. Buenos Aires.

Acosta, A. e Mucciolo, L. 2009. Zooarqueologia dos grupos horticultores amazonicos no rio Parana inferior: o caso do sítio Arroyo Fredes. Revista de Arqueologia 22(1) 43 - 63.

Afonso, M.C.; Sallum, M. e Lopes, M.2010. Ocupações ceramistas tupi e Jé em São Paulo: Espacialização e cronologia. Anais do XV Congresso da Sociedade de Arqueologia Brasileira, parte I: 8-15.

Ambrosetti, J. 1893. Los cementerios prehistóricos del Alto Paraná (Misiones). Boletín del Instituto Geográfico Argentino 16: 227263. Buenos Aires.

Andrefsky, W. 1994. Raw-Material Availability and the Organization of Technology. American Antiquity 59 (1): 21-34. 
Andrefsky, W. 2005. Lithics. Macroscopic Approaches to Analyses. Cambridge: Cambridge University Press.

Alonso, M. e Prous, A. 2003. Estudo de conjuntos líticos Tupiguaraní. Anais do XII congresso nacional de arqueologia brasileira. 21 25 de setembro 2003. São Paulo.

Aschero, C. 1975. Ensayo para una clasificación morfológica de artefactos líticos aplicada a estudios tipológicos comparativos. Informe al CONICET. Buenos Aires, Ms.

Aschero, C. 1983. Ensayo para una clasificación morfológica de artefactos líticos aplicada a estudios tipológicos comparativos. Apéndices A - C. Revisión. Cátedra de Ergología y Tecnología (FFyL-UBA). Buenos Aires, Ms.

Binford, L. R. 1979. Organization and formation processes: looking at curated technologies. Journal of Anthropological Research 35(3): 255-273.

Blumenschine, R. J.; Masao, F.T.; Tactikos, J.C. e Ebert, J.I. 2008. Effects of distance from stone source on landscape-scale variation in Oldowan artifact assemblages in the Paleo-Olduvai Basin, Tanzania. Journal of Archaelogical Science 35: 76-86.

Bogan, S. 2005. Análisis del material faunístico del sítio arqueológico Arenal central, Isla Martín García. Trabajo presentado en VI Jornadas Chivilcoyanas en Ciencias Sociales y Naturales (CDROM). Chivilcoy, Centro de Estudios en Ciencias Sociales y Naturales.

Brantingham, P.J. 2005. A neutral model of stone raw material procurement. American Antiquity 68(3): 487-509.

Brochado, J.P. 1984. An Ecological Model of the Spread of Pottery and Agriculture Into Eastern South America. Tese de doutorado. Carbondale: University of Illinois at Urbana-Champaign.
Burmeister, H. 1872. Uber Altherhumer am Río Negro und Río Paraná. Verhandlungen der Berliner Gesellschft fur Ethnologie und Urgechichte, 196-197.

Capparelli, I. 2007. Martín García antes del despensero de Solís. XVI Congreso Nacional de Arqueología Argentina, Tomo 1: 163-166. Jujuy.

Capparelli, I. 2014. Estudio de las Ocupaciones Indígenas Prehispánicas en la Isla Martín García. Argentina. Tese de doutorado. La Plata: FCNyM, UNLP.

Carbonera, M. e Loponte, D. 2014. Arqueologia da Floresta Atlântica Meridional Sul Americana: resultados preliminares das pesquisas arqueológicas do projeto binacional. Trabalho apresentado no $2^{\circ}$ Congresso Internacional de Arqueologia da Bacia do Prata, San José de Mayo 7-11 de abril de 2014.

Caggiano, M.A. e Prado, J.L. 1991. Aporte al conocimiento de la tradición tupiguarani. Revista del Museo de la Plata (Nueva Serie), Tomo IX: 129-165. Buenos Aires.

Cigliano, M.E. 1968. Investigaciones arqueológicas en el Río Uruguay medio y la costa NE de la Prov. de Buenos Aires. Pesquisas 18: 5-9, Instituto Anchietano, Brasil.

De Masi, M.A. e Schmitz, P.I. 1987. Análise dos artefatos líticos de fases da Tradição Tupiguarani do Rio Grande do Sul. Arqueologia do Rio Grande do Sul - Série Documentos 1: 49-98.

Grupo Consultor Mesopotámico. 2006 - 2009. Estudio Geológico e Hidrogeológico de la Provincia de Misiones.

Hoeltz, S.E. 2005. Tecnologia Litica: uma Proposta de Leitura para a Compreensão das Indústrias do Rio Grande do Sul, Brasil, em Tempos Remotos. Tese de doutorado. Porto Alegre: Faculdade de Ciências Humanas, PUCRS. 
INSUGEO 2007. Sinopsis estratigráfica de La Mesopotamia. Serie Correlación Geológica 22: 47-116.

Josse, C.; Navarro, G.; Comer, P.; Evans, R.; Faber-Langendoen, D.; Fellows, M.; Kittel, G.; Menard, S.; Pyne, M.; Reid, M.; Schulz, K.; Snow, K.; e Teague, J. 2003. Ecological Systems of Latin America and the Caribbean: A Working Classification of Terrestrial Systems. Arlington: NatureServe.

Léry, J. de 1972. Viagem à terra do Brasil. São Paulo: Martins/EDUSP.

Lima, A. P. 2005. Função dos calibradores e sua inserção na cultura material Tupíguarani, Monografia de graduação. Belo Horizonte: UFMG.

Lima, A. P. e Souza, G. 2005. Experimentação de uso de calibradores: Fabricação de hastes pontas e tembetás. Trabalho apresentado no XIII Congresso da SAB, Campo Grande.

Lopes, M. e Moraes Wichers, C.A. 2009. Ocupações ceramistas Tupiguarani na região norte do estado de São Paulo. Trabalho apresentado no XV Congresso da Sociedade de Arqueologia Brasileira, Belém.

Loponte, D. 2008. Arqueología del Humedal del Paraná inferior (Bajios Ribereños Meridionales). In Loponte, D. e Acosta, A. (Eds). Serie Monográfica Arqueología de la Cuenca del Plata. Buenos Aires: Instituto Nacional de Antropología y Pensamiento Latinoamericano.

Loponte, D. e Acosta, A. 2003-2005. Nuevas perspectivas para la arqueología "Guaraní" en el humedal del Paraná inferior y Río de la Plata. Cuadernos 20: 179-197.

Loponte, D. e Acosta, A. 2007. Horticultores amazónicos en humedal del Paraná inferior: los primeros datos isotópicos de la dieta. In Bayón, C.; Pupio, A.; González, M.I.; Flegenheimer, N. e Frére, . (Eds.). Arqueología en las Pampas, 75-93. Sociedad Argentina de Antropología.

Loponte, D. e Acosta, A. 2008. Estado actual y perspectivas de la arqueología de la "Tradición Tupí-guaraní" en Argentina. In Lima, T.A. e Prous, A. (Eds.)., Os Ceramistas Tupiguarani, Vol. 1: 181-196.

Loponte, D. e Acosta, A. 2013. La construcción de La unidad arqueológica guaraní en el extremo meridional de su distribución geográfica. Cuadernos del Instituto Nacional de Antropología y Pensamiento Latinoamericano - Series Especiales 1(4): 193-235.

Loponte, D., Acosta, A.; Capparelli, I. e Perez, M. 2011. La arqueología guaraní en el extremo meridional de la cuenca del Plata. In Loponte, D. e Acosta, A. (Eds.) Arqueología Tupiguaraní, 111-154. Buenos Aires: AINA.

Loponte, D.; Carbonera, M. e Acosta, A. 2014. Os valores isotópicos da dieta entre grupos horticultores na Bacia do Prata. Trabalho apresentado na IX Reunião da Sociedade de Arqueologia Brasileira - Núcleo Regional Sul. "Arqueologia, Patrimônio e Interdisciplinaridade: desafios contemporâneos". 14 a 17 de outubro de 2014. Joinville/SC.

Lothrop, S. 1932. Indians of the Paraná Delta River. Annals of the New York Academy of Sciences XXXIII: 77-232.

Luz, J. A. R. e Faccio, N.B. 2006. A pedra lascada dos índios guarani, pré-históricos, a partir de uma análise tecnológica. Anais do $V$ encontro do Núcleo Regional Sul da Sociedade de Arqueologia Brasileira - SAB/Sul. De 20 a 23 de novembro de 2006, Rio Grande, RS.

Menghin, O. 1955/1956. El Altoparanaense. Ampurias XVII-XVIII: 171-200.

Menghin, O. 1957. El poblamiento prehistórico de Misiones. Anales de Arqueología y Etnología XII: $19-40$. 
Menghin, O. 1962. Observaciones sobre la arqueología Guaraní de Argentina y Paraguay. Jornadas Internacionales de Arqueología y Etnografía, 54-68. Buenos Aires.

Métraux, A. 1928. La Civilisation Matérielle des Tribus Tupi-Guarani. París: Librarie Orientaliste.

Milheira, R.G. e Alves, A.G. 2009. O sítio Guaraní PS 03 Totó: uma abordagem cultural e sistêmica. Revista de Arqueologia 22(1): 15-41.

Moraes C. A. 2007. Arqueologia Tupi no Nordeste de São Paulo: Um Estudo de Caso de Variabilidade Artefatual. Dissertação de mestrado. São Paulo: Museu de Arqueologia e Etnologia, USP.

Morales, W. F. 2005. 12.000 anos de ocupação: Um estudo de Arqueologia Regional na Bacia do Córrego Água Fria, médio curso do Rio Tocantins. Tese de doutorado. São Paulo: USP.

Mujica, J. I. 1995a. De Corrientes Argentina. Informe de dos sítios arqueológicos guaraní en la provincia. XV Encuentro de Geohistoria Regional. Gdor. Virasoro, 119. 128.

Mujica, J.I. 1995b. Un sítio guaraní en el centro de la provincia de Corrientes.- Llamarada-Sta. Rosa. Depto. De Concepción. XV Encuentro de Geohistoria Regional. Gdor. Virasoro, 135- 148.

Mucciolo, L. 2007. Explotación y procesamiento de ungulados en el sítio Arroyo Fredes. In Bayón, C.; Pupio, A.; González, M.I.; Flegenheimer, N. e Frére, M. (Eds.). Arqueología en las Pampas, 591-614. Sociedad Argentina de Antropología.

Newman, J. R. 1994. The effects of the distance on lithic material reduction technology. Journal of Field Archaeology 21(4): 491-501.

Noelli, F.S. 2004. La distribución geográfica de las evidencias arqueológicas guaraní. Revista de Indias LXIV (30): 17-34.
Olson, D.M; Dinerstein, E.; Wikramanayake, E.D.; Burgess, N.D.; Powell, G.V.N.; Underwood, E.C.; D’Amico, J.A.; Itoua, I.; Strand, H.E.; Morrison, J.C.; Loukes, C.J.; Allnutt, T.F.; Ricketts, T.H.; Kura, Y.; Lamoreux, J.F.; Wettengel, W.W.; Hedao, P. e Kassem, K.R. 2001. Terrestrial Ecoregions of the World: A New Map of Life on Earth. Bioscience 51(11): 933-938.

Outes, F. 1917. Primer hallazgo arqueológico en la isla Martín García. Anales de la Sociedad Cientifica Argentina LXXXII: 265-277.

Outes, F. 1918. Nuevos rastros de la cultura Guaraní en la cuenca del Paraná inferior. Anales de la Sociedad Cientifica Argentina LXXXII: 153-182.

Pestana, M.B. 2007. A tradição Tupiguarani na Porção Central da Planície Costeira do Rio Grande do Sul, Brasil. Dissertação de mestrado. São Leopoldo: Centro de Ciências Humanas, UNISINOS.

Poujade, R. 1995. Mapa arqueológico de la provincia de Misiones - E.B.Y. Subsecretaría de la provincia de Misiones.

Prous, A. 2011. Estudios sobre los portadores de la cerámica tupíguaraní en Brasil: proto-Tupí, proto-Guaraní y otros... In Loponte, D. e Acosta, A. (Eds.) Arqueología Tupiguarani, 23-109. Buenos Aires: Instituto Nacional de Antropología y Pensamiento Latinoamericano.

Remesal, M.; Chávez, S. 2014. Tipos y distribución de los basaltos en Misiones. Trabalho apresentado no $1^{\circ}$ Taller de Recursos Líticos del Nordeste Argentino. Paraná 22 de Agosto de 2014.

Rizzo, A. 1968. Distribución de sítios arqueológicos en el Departamento Eldorado, Misiones. Pesquisas 20: 131-134.

Rizzo, A. 1969. Noticias sobre algunos talleres líticos ubicados en las costas del río Alto 
Paraná. Pcia. de Misiones. Pesquisas, Antropología 20: 112-115. São Leopoldo.

Rizzo, A.; Shimko, S. 2003. La tradición Tupiguaraní misionera. Actas XIII Congreso Nacional de Arqueología Argentina, 115 . 128. Córdoba.

Rodríguez, J. 1994. Nuevos aportes para la arqueología de la provincia de Corrientes. Actas del XI Congreso Nacional de Arqueología Argentina. San Rafael, Mendoza.

Rodríguez, J. 1996. Investigaciones Arqueológicas en Yaciretá (Corrientes, Argentina). Actas de las Jornadas de Antropología de la Cuenca del Plata III: 41-54.

Rodríguez, J. 2004. En busca de la tierra sin mal. El poblamiento de la cuenca del Plata por los guaraníes prehistóricos. Ciencia Hoy 14(80): 28-33.

Rodríguez, J. 2008. Arqueología de humedales en la provincia de Corrientes (Argentina). In: Loponte, D. e Acosta, A. (Eds.). Arqueología de Humedales del Este de Sudamérica, 165-190. Buenos Aires: Editorial Los Argonautas.

Sempé, M.C.; Caggiano M.A. 1995. Las culturas agroalfareras del Alto Uruguay (Misiones, Argentina). Revista do Museu de Arqueologia e Etnologia 5: 27-38.

Sempé, M.C.; Rizzo, A. 2000. El uso del espacio entre cazadores y agricultores prehispánicos en Misiones R.A. Actas XX Encuentro de Geohistoria Regional: 927-937.
Silvestre, R. 2010. Análisis Funcional de Artefactos Líticos del Humedal del Paraná Inferior: El Sitio Túmulo de Campana Como Caso de Estudio. Tese de Licenciatura. Buenos Aires: UBA.

Silvestre, R. 2013. Estrategias tecnológicas de grupos guaraníes prehistóricos: el sítio $\mathrm{A}^{\circ}$ Fredes como caso de estudio. Humedal del Paraná inferior, Argentina. Cuadernos del Instituto Nacional de Antropología y Pensamiento Latinoamericano - Series Especiales 1(2): 279-301.

Silvestre, R.; Capparelli, I. 2014. Comparando registros: La tecnologia lítica de grupos horticultores prehispánicos en la cuenca del Plata. Trabalho apresentado no $2^{\circ}$ Congresso Internacional de Arqueologia da Bacia do Prata, San José de Mayo 7-11 de abril de 2014.

Silvestre, R.; Buc, N. 2015. Experimentação e traceologia: explorando a funcionalidade dos "calibradores" dos sítios arqueológicos de tradição tupizguarani, Argentina. Teoria e Sociedade 23(1): 44-70, (no prelo)

Torres, L.M. 1911. Los Primitivos Habitantes del Delta del Paraná. Universidad Nacional de La Plata. Biblioteca Centenaria. La Plata.

Vignati, M.A. 1936. Arqueología de la Isla Martín García. Physis 12. Buenos Aires.

Wagner, G.P. 2003. Analise do material lítico proveniente dos sítios arqueológicos encontrados ás margens da BR - 101: Trecho Torres-Osorio, RS. Comunicação apresentada no XII Congresso da Sociedade de Arqueologia Brasileira. 21-25 de 